\title{
'Mind the Gap': why HIV-positive gay men deserve the best from health services, and where they're not getting it
}

\section{Susan Quilliam}

\section{Background}

Unusually for me, I want to take as a starting point for this article a personal event: the diagnosis with HIV of an old friend of mine. A bright, effective, loving gay man whom I shall call Martin - the very fact that he has asked for his name to be changed should give you some forewarning about the theme I am following - his condition shocked but did not destroy him. He has coped amazingly well with the diagnosis, as have his family, his friends and his partner.

Which makes it all the sadder that the one place where those around Martin did not step up to the challenge has been in the health service. Yes, his HIV doctor has been "wonderful" and the supporting team has been "effective and compassionate". But when it comes to primary care, Martin has not, unfortunately, been able to use the same adjectives; instead he has been struck by the much less impressive approach adopted by his non-specialist providers - both health professionals and administrative staff. It is this that has spurred me on to write this article, speaking to both HIV clients and health professionals, as well as leaning heavily on existing research and interviews done by the sterling Terrence Higgins Trust (THT).

Let me first say, however, that I am not on a witch hunt here. I am in no way suggesting that primary care staff in general fall short in the treatment of gay men who are HIV positive. In the course of my research I heard numerous accounts of good practice.

Such accounts have come from HIV-positive patients: "I have disclosed to each GP I have had in the last 19 years and they have all showed no outward signs of judgement or hesitation" and "My local doctor has always been most supportive and I have never had even a sideways look from a receptionist". Stories have come from HIV health professionals: "We have a local GP who is aware of how to make urgent referrals", "some years back [there were] financial incentives for surgeries to provide an Enhanced Sexual Health Service in-house" and "our practice had training, where we got to work with HIV consultants; very useful indeed".

Nevertheless, for the sake of all our reputations, I do feel that failings in the primary care noted by my interviewees ought to be highlighted so that we can challenge them.

\section{Where our approach falls short}

The shortcomings that my respondents identified were threefold. First, a lack of medical knowledge about HIV in primary care, sometimes leading to misdiagnosis or mistreatment. "I have attended my GP surgery in the last few years for chest infections and [typically] my GP will provide a week of antibiotics which do not clear the problem. [My HIV clinic] then says 'they shouldn't have given you that', at which point I take a second round". In particular, clients complained of the lack of awareness of drug interactions on

J Fam Plann Reprod Health Care 2010; 36(3): 175-176

\section{Cambridge, UK}

Susan Quilliam, BA, Cert Ed, MNLP, Freelance Writer, Broadcaster and Agony Aunt

Correspondence to: Ms Susan Quilliam.

E-mail: susan@susanquilliam.com the part of GPs, leading to ill-advised prescriptions for such conditions as high blood pressure or high cholesterol, which in turn can result in serious side effects.

The second issue noted was lack of co-ordination in services. HIV clinicians, perhaps because they have historically not needed to make contact with and fully inform non-specialist staff, may sometimes not be proactive in doing so. But where contact is made, primary care professionals, perhaps because they are fearful of disclosing the identity of HIV patients, may be unwilling to respond.

Plus, perhaps because of nervousness (in turn based on lack of medical knowledge), primary care workers may step aside from diagnosis and treatment and refer back to the HIV clinic, thus wasting both client and professional time and money.

The third strand of complaint in my interviewees' view concerned discrimination and lack of empathy. One HIV worker reported "the letters HIV (often written large) across the front of client notes in one surgery". Another interviewee overheard "blaming moral judgments by primary care professionals about how clients may have contracted HIV". And such stories are not figments of my sources' imaginations. A recent survey of people with HIV showed that one in five respondents had experienced discrimination in the preceding year from doctors or other health care professionals. ${ }^{1}$

In particular, both HIV professionals and clients pinpointed dental services as especially guilty of refusing treatment, or imposing unnecessary restrictions in order to discourage clients from signing up. ${ }^{2}$ One example often quoted was of dentists insisting on end-of-the-day appointments, supposedly to avoid cross-infection, which as one health worker commented "is of course nonsense, since all instruments should be thoroughly sterilised between all patients".

When it comes to lack of empathic awareness, perhaps the most horrifying story, quoted in THT's moving document, 21st Century HIV, ${ }^{3}$ was of a gay man who received his diagnosis over the telephone. "We were eating our tea ... I answered the phone and was put through to my GP [who said]: 'I've had the results of your test, you're positive, you'd better come and see me. I'm busy now, goodbye'. And that was it."

\section{Why our approach falls short}

Let us consider why these problems are happening. Ironically, of course, the main reason is that HIV is no longer an automatic death sentence - the development of highly active anti-retroviral therapy (HAART)) has made it more logical for non-HIV-related health matters to be treated in the primary care arena rather than by specialists - with the added attraction that this will theoretically cut costs.

\section{HIV is no longer an automatic death sentence.}

The move comes after several decades in which HIV management has been specialised - one of my interviewees used the word "ghettoised" - and therefore even aside from the specialist expertise that primary care staff may need in order to cope, they have often not had the chance to build 
up any basic knowledge or experience of HIV issues. Where this lack is not supported by sufficient training and resources, even the best-meaning primary care professionals are working at a disadvantage. (Plus, of course, in primary care practices HIV is only one of the many issues dealt with each day, leading to even more strain on the system.)

This strain is compounded by a trend which I have often bemoaned in this column: the embarrassment of health service professionals - both medical and administrative around matters sexual. (Clients of course also suffer from reticence, but then they have not been professionally tasked with providing a service.) The mention of HIV particularly when paired with a client's gay sexuality - can all too often be not only a trigger for general wariness, but also a trigger for any inbuilt sexual inhibition and prejudice to occur. For primary care workers in particular, who don't have not the frontline experience that HIV specialists have gained, this unwillingness - which may come from early childhood, upbringing, personal sexual experiences - has never been challenged or eroded. Talking freely and objectively about HIV can be a huge mountain for staff to climb.

\section{The mention of HIV can be a trigger for any inbuilt sexual inhibition and prejudice to occur.}

The end result of all these factors? Of course, all-round frustration, anger and depression. Of course, professional stress, strain, anxiety and demotivation. Of course, client unwillingness to disclose their status and, presumably, an unwillingness of those who hear such horror stories to be tested for HIV in the first place. But crucially, a lack of effective and supportive care for HIV sufferers, a greater strain on health services, and hence - let us be blunt - a potentially higher mortality rate.

\section{What we can do}

Possible action points? My interviewees suggested many. Let's begin with what policymakers could do: perhaps for starters they could allocate more funding to the cause. And perhaps the primary care trusts (PCTs) could then back the appropriate allocation of this funding without, please, any more incidents such as followed the 2004 allocation of $£ 315$ million to sexual health services, when 161 of the 191 PCTs diverted some or all of their funding away from the specified area.

Given such funding, all my interviewees, and the THT spokesperson, made specific recommendations that could go a long way to remedy the situation. [NB. The organisations listed in Box 1 may be able to help with further information and support.] Set up more training of primary care professionals in HIV-related matters. Make HIV an important part of continuing professional development. Fund liaison between HIV specialists and primary care staff (and of course HIV-positive clients). In particular, fund the lowering of the anxiety level around HIV and around different sexual lifestyles, so that staff of all kinds are more able to take the training on board without shying away.

A further improvement that would help enormously both in terms of patient care and in terms of normalisation and acceptance of HIV - has of course already been formally suggested, as some of my interview cohort reminded me. The UK National Guidelines for HIV Testing ${ }^{4}$ suggest giving primary care staff parallel responsibility to test for HIV, especially when clients
Box 1: Organisations that support client and professional understanding of HIV issues

- National AIDS Trust - UK HIV policy development and campaigning organisation (www.nat.org.uk)

- Terrence Higgins Trust - the UK's largest HIV and sexual health service provider (www.tht.org.uk)

- British Association for Sexual Health and HIV (BASHH) forum for sexual health and HIV clinicians (www.bashh.org)

- British HIV Association - forum for HIV practitioners (www.hbiva.org)

present with linked illnesses and particularly in highprevalence areas. This, as one interviewee pointed out, "would not only reduce HIV but also normalise the testing process and raise awareness among health workers ... and the general public".

Which leads neatly on to the point that, of course, no professionally targeted programme will succeed if it is not backed by solid public education. The 'man in the street' is increasingly aware that HIV is no longer an inevitable death sentence, but that doesn't mean that he (and she) shouldn't take the illness seriously, offer empathy and understanding to HIV sufferers, and realise that they are not to blame for their condition. Whatever can be done to encourage such attitudes should be done, whether that is through sexual health awareness programmes or through careful and strategic enrolment of the health press.

In the final call to action - which asks for even more courage from HIV clients - several of my interviewees wanted such clients to disclose their status, to challenge discrimination, and thus to actively involve primary staff in care. As one interviewee put it: "If we do not stand up for our rights and come clean about all our health conditions, we cannot expect to be treated appropriately".

Let me end, then, with a comment from my friend Martin: "Like all patients, people with HIV deserve the best possible care from all sides of the health service". Which in my view is not only an excellent summary of what clients, professionals and public alike are surely signing up to, but is also a summary of what clients, professionals and public alike are surely signing up to but is also a pretty good summary of what this article is all about.

\section{Acknowledgements}

The author wishes to thank all interviewees: those who asked not to be named, Jonathan and, above all, Martin. Particular thanks are also due to the Terrence Higgins Trust for permission to quote from interviews and resources included in their resource, 21st Century $H I V$, which is downloadable from their website at www.tht.org.uk.

Statements on funding and competing interests

Funding None identified.

Competing interests None identified.

\section{References}

1 Sigma Research. What Do You Need? 2007-08: A Health, Social Care, Support and Information Needs Assessment of People with Diagnosed HIV in the UK. http://www. sigmaresearch.org.uk/go.php/projects/project36 [Accessed 22 April 2010]

2 Elford J, Ibrahim F, Bukutu C, Anderson J. HIV-related discrimination reported by people living with HIV in London, UK. AIDS Behav 2008; 12: 255-264.

3 Terrence Higgins Trust, the British Association of Sexual Health and HIV. 21st Century HIV: Personal Accounts of Living and Working with HIV in Modern Britain. http://www.tht.org.uk/ informationresources/publications/policyreports/twentyfirstcent uryhiv.pdf [Accessed 22 April 2010].

4 British HIV Association, British Association of Sexual Health and HIV, British Infection Society. UK National Guidelines for HIV Testing 2008. 2008. http://www.bashh.org/documents/ 1838 [Accessed 22 April 2010]. 